\title{
Intracranial hypertension and empty Sella from adrenal adenoma and excessive and prolonged steroid usage: a case report
}

\author{
Naiqian Zhao ${ }^{1 *}$, Weixia Yang ${ }^{1}$, Xiaoyan $\mathrm{Li}^{2}$, Li Wang ${ }^{1}$ and Ying Feng ${ }^{1}$
}

\begin{abstract}
Background: There is only one documented case of intracranial hypertension $(\mathrm{IH})$ and empty sella from cortisolproducing adrenal adenoma so far. And $\mathrm{IH}$ and empty sella caused by long-term exogenous hypercortisolism has never been reported before. The purpose of this case report is to alert clinicians to glucocorticoid-induced $\mathrm{IH}$.

Case presentation: We present retrospectively a 50-year-old woman with cortisol-secreting adrenal adenoma, who progressed to intractable intracranial hypertension and a markedly expanded empty sella due to improper treatment. In 2011, the patient presented with hypertension, lack of cortisol circadian rhythm, low ACTH, a left adrenal adenoma and a partial empty sella, but did not receive low-dose dexamethasone suppression test (LDDST) and 24-h urinary cortisol. In 2014, she exhibited truncal obesity, raised cortisol, LDDST non-suppression, high urinary free cortisol and low ACTH, proving her cortisol-producing adrenal adenoma. She was simultaneously diagnosed with unexplained $\mathrm{IH}$ because of papilledema and elevated intracranial pressure, and her partial empty sella changed to a complete empty sella. In 2015, she underwent adrenal adenoma resection. From 2015 to 2018, she kept taking dexamethasone at least $2 \mathrm{mg}$ daily without her doctors' consent. During this period, she developed transient cerebrospinal fluid rhinorrhea, and her empty sella further worsened. After switching to low dose hydrocortisone, her papilledema disappeared completely, but optic atrophy has become irreversible.

Conclusions: The patient seems to be just an extreme case, but it may reveal and illustrate a general phenomenon: Both cortisol-producing adrenal adenoma and long-term exogenous hypercortisolism could cause varying degrees of elevated intracranial pressure and empty sella. Clinicians should remain vigilant for this phenomenon in patients with cortisol-producing adrenal adenoma or excessive and prolonged steroid usage and give them corresponding examinations to identify this complication.
\end{abstract}

Keywords: Adrenal adenoma, Exogenous hypercortisolism, Intracranial hypertension, Empty Sella, Papilloedema

\section{Background}

Idiopathic intracranial hypertension (IIH) is a clinical syndrome characterized by increased intracranial pressure of unclear etiology. Its most common pathological changes are papilledema and empty sella. If untreated or improperly treated, papilledema can lead to progressive

\footnotetext{
* Correspondence: m18235150464@163.com

'Department of Gerontology, Second Hospital of Shanxi Medical University, Wuyi Road 382\#, Taiyuan 030001, China

Full list of author information is available at the end of the article
}

and irreversible vision loss as a result of optic atrophy, and empty sella can cause hypothalamic-pituitary dysfunction and resultant hormonal alterations [1, 2]. Although the underlying cause of IIH is still unknown, many studies indicate that Cushing disease, chronic steroid administration and acute withdrawal of chronic steroid use are among the largely reported possible causal and associated risk factors [3]. In 1980, Britton et al. reported that there is an association between IIH and cortisol-secreting adrenal adenoma [4]. Since then,

(c) The Author(s). 2022 Open Access This article is licensed under a Creative Commons Attribution 4.0 International License, which permits use, sharing, adaptation, distribution and reproduction in any medium or format, as long as you give appropriate credit to the original author(s) and the source, provide a link to the Creative Commons licence, and indicate if changes were made. The images or other third party material in this article are included in the article's Creative Commons licence, unless indicated otherwise in a credit line to the material. If material is not included in the article's Creative Commons licence and your intended use is not permitted by statutory regulation or exceeds the permitted use, you will need to obtain permission directly from the copyright holder. To view a copy of this licence, visit http://creativecommons.org/licenses/by/4.0/ The Creative Commons Public Domain Dedication waiver (http://creativecommons.org/publicdomain/zero/1.0/) applies to the data made available in this article, unless otherwise stated in a credit line to the data. 
however, no other cases associated with cortisolsecreting adrenal adenoma have been reported. It is unknown whether IIH with cortisol-secreting adrenal adenoma has not been given due attention by the academia or it's just an individual and accidental phenomenon.

\section{Case presentation}

In 2020, a 50-year-old female was admitted to our hospital with persistent blurred vision. In 2011, she presented with high blood pressure. Her blood cortisol $(\mathrm{nmol} / \mathrm{L})$ was 324.0 (8 am, reference 171-536), 336.2 (4 pm, reference 64-327) and 303.5 (12 pm). Adrenocorticotrophic hormone $(\mathrm{ACTH})$ was $<0.220 \mathrm{pmol} / \mathrm{L}$ (reference 1.10-13.2). She did not receive low-dose dexamethasone suppression test (LDDST) and 24-h urinary cortisol. Pituitary magnetic resonance imaging (MRI) revealed a partial empty sella and adrenal computed tomography (CT) showed a left adrenal mass (Fig. 1A). She was diagnosed with left adrenal adenoma. Her physician suggested making an adrenal CT scan every 3-6 months to observe the change of left adrenal mass. After that, she made frequent medical visits to different hospitals due to various non-specific symptoms such as general fatigue and facial edema. In 2014, she was admitted with truncal obesity, fragile fracture and blurred vision. Her blood cortisol (nmol/L) rose to 429.1, 470.4 and 404.9. ACTH was still $<0.220 \mathrm{pmol} / \mathrm{L}$. LDDST showed that blood cortisol $(\mathrm{nmol} / \mathrm{L})$ was 427.8 ( $8 \mathrm{am}$, preLDDST) and 438.9 ( $8 \mathrm{am}$, post-LDDST). Twenty-fourhour urinary free cortisol $(\mathrm{nmol} / 24 \mathrm{~h})$ was 664.86 (reference 100-379). Pituitary MRI showed a complete empty sella and adrenal CT showed no significant changes in the left adrenal mass (Fig. 1B). Bone mineral density by dual energy X-ray absorptiometry established the diagnosis of osteoporosis. Fundus examination confirmed bilateral papilloedema. Lumbar puncture revealed cerebrospinal fluid (CSF) pressure was more than $330 \mathrm{mmH}_{2} \mathrm{O}$. She was diagnosed with cortisol-producing adrenal adenoma. Her surgeon considered that the cause of her intracranial hypertension $(\mathrm{IH})$ was unknown and $\mathrm{IH}$ was a contraindication for adrenal surgery, so she was referred to multiple superior hospitals for further evaluation. Her cerebral MRI and angiography excluded intracranial mass, aneurysm and venous sinus thrombosis. She was then diagnosed with unexplained IH. In 2015, she underwent adenoma resection. Histological examination and immunohistochemical study of the resected specimen revealed an adrenocortical adenoma on the left side. After the operation, her surgeon told her she needed constant steroid treatment. From 2015 to 2018, she kept taking dexamethasone at least $2 \mathrm{mg}$ daily without her doctors' consent. Years of seeking medical attention brought a heavy financial burden on her family and the diagnosis of unexplained $\mathrm{IH}$ made her lose confidence in treatment. These were why she kept taking dexamethasone and didn't turn to her doctors again. During this period, she had a further worsening in truncal obesity and blurred vision, and she also developed transient CSF rhinorrhea. In 2018, she was diagnosed with renal tuberculosis because of intermittent fever. Her physician judged glucocorticoid excess was her cause of renal tuberculosis. Her glucocorticoid treatment was then revised to hydrocortisone 20 $\mathrm{mg}$ at $8 \mathrm{am}$ and at $4 \mathrm{pm}$. By 2020, her truncal obesity completely disappeared but blurred vision remained. Pituitary MRI showed a markedly enlarged empty sella and a severe eroded sellar floor, and adrenal CT was normal (Fig. 1C). Fundus examination revealed no papilledema. Optical coherence tomography indicated bilateral optic atrophy (Fig. 2).

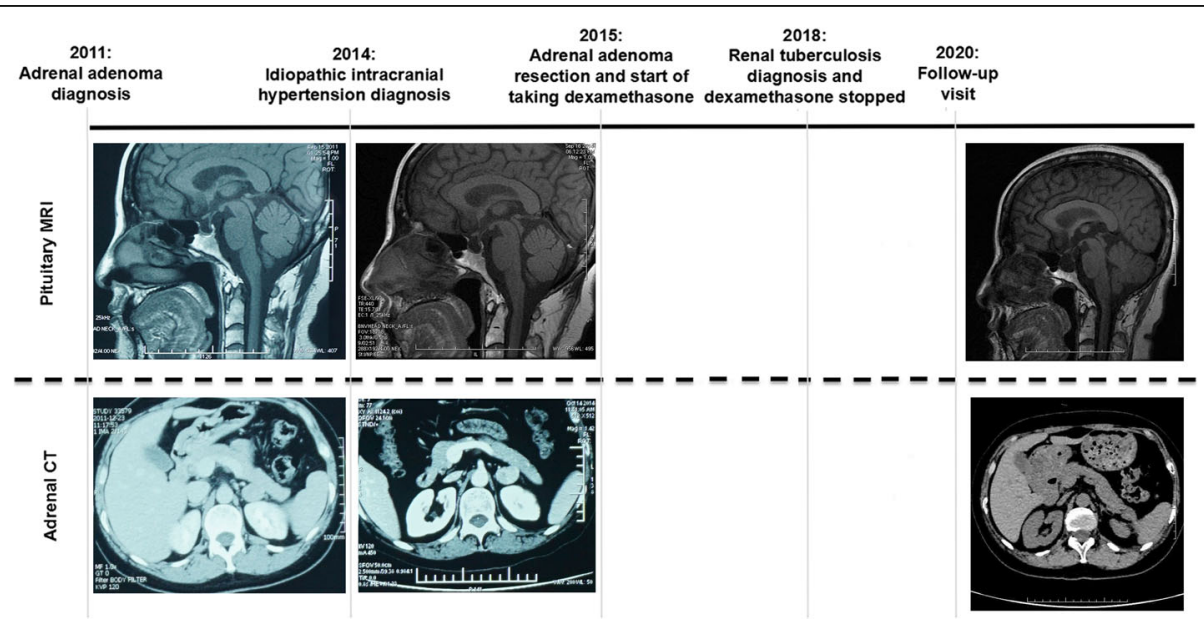

Fig. 1 Chronology of diagnosis and treatment. Shown is a summary of diagnosis and treatment. Pituitary MRI shows progressively worsening empty sella and sellar floor erosion from 2011 to 2020. Adrenal CT shows no significant morphological changes in the left adrenal mass from 2011 to 2014. A 2011; (B) 2014; (C) 2020 

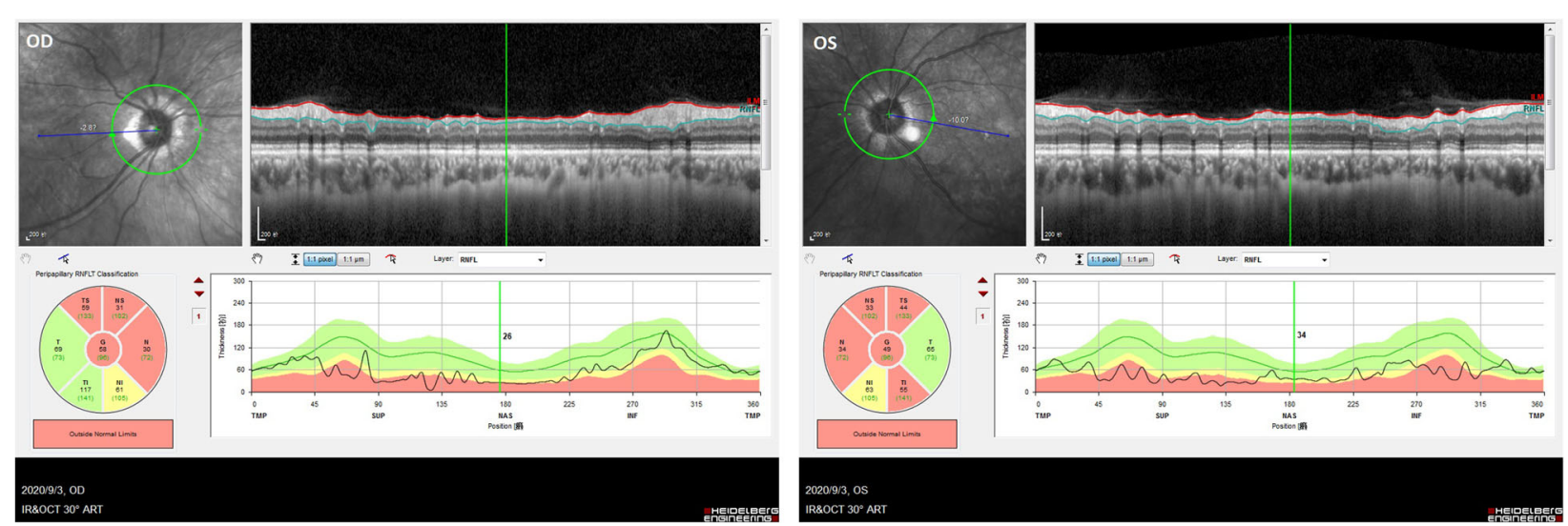

Fig. 2 Optical coherence tomography. Optical coherence tomography shows bilateral retinal nerve fiber layer thinning in the peripapillary, more prominent in the left eye

\section{Discussion and conclusions}

The patient had been through two stages. Before adrenal adenoma excision, she progressively exhibited a cluster of hallmark symptoms of Cushing's syndrome from hypertension to truncal obesity and fragile fracture. Laboratory examinations showed that her cortisol circadian rhythm was not present, blood ACTH was undetectable, urinary free cortisol was significantly higher than the normal range, and low doses of dexamethasone didn't decrease cortisol secretion. Adrenal CT revealed a left adrenal mass. All of these prove that the patient had cortisol-producing adrenal adenoma. In addition, the patient was also found to have $\mathrm{IH}$ and worsening empty sella.

There is only one documented case of $\mathrm{IH}$ and empty sella from cortisol-producing adrenal adenoma so far [4]. However, this doesn't mean that $\mathrm{IH}$ and empty sella is a rare manifestation of this disorder. As this case shows, the patient's empty sella had existed when her adrenal adenoma was first found, which suggests that despite the lack of symptoms of $\mathrm{IH}$, her intracranial pressure might have risen above the normal level, because prolonged increased intracranial pressure is one of the many reasons of empty sella. When she was diagnosed with unexplained IH, her empty sella was exacerbated. Meanwhile, she presented with a characteristic cluster of symptoms such as truncal obesity and fragile fracture, and many non-specific symptoms such as general fatigue, facial edema and blurred vision. If her blurred vision was ignored and wasn't traced to raised intracranial pressure, her IH wouldn't be found. The disease's progression implies that cortisol-producing adrenal adenoma can lead to $\mathrm{IH}$ and empty sella, and elevated intracranial pressure might be a universal presentation of this disorder but just be neglected due to the lack of noticeable symptoms in early stage or be covered up by other symptoms in later stage. However, this conjecture needs to be further confirmed by more patients with cortisol-producing adrenal adenoma.

After adrenal adenoma excision, the patient continuously misused high-dose dexamethasone, and, as a result, her symptoms of Cushing's syndrome and $\mathrm{IH}$ and her empty sella became more evident and serious. Corticosteroids are frequently used for treating inflammatory and immune-mediated diseases. In some immunemediated diseases, IH has been described during corticosteroid treatment $[5,6]$. Corticosteroids-induced $\mathrm{IH}$ is regarded as a rare adverse efect [5]. This patient had no inflammatory or immune-mediated diseases, which can exclude the possibility of $\mathrm{IH}$ from a complex interaction between these diseases and corticosteroids. This case suggests that prolonged corticosteroids might inevitably raise intracranial pressure and cause empty sella, but in most cases, these changes are just not to the extent of being perceived. However, this conjecture also needs to be further confirmed by more patients taking corticosteroids.

CSF hypersecretion may have a causative role in glucocorticoid-induced $\mathrm{IH}$. There is a possible mechanism for the effect of glucocorticoids on CSF production $[1,7]$. In epithelial choroid plexus cells, glucocorticoids can activate $11 \beta$-hydroxysteroid dehydrogenase type 1 (11 $\beta$-HSD1). 11 $\beta$-HSD1 converts cortisone to cortisol, and cortisol can activate mineralocorticoid receptors and drive $\mathrm{Na}^{+} / \mathrm{K}^{+}$ATPase activity, thereby increasing CSF production.

In summary, this case clearly shows how IH and empty sella were gradually formed and accentuated with greater levels of continuous hypercortisolism. The patient seems to be just an extreme case, but it may reveal a general phenomenon: Both cortisol-producing adrenal adenoma and long-term exogenous hypercortisolism could cause varying degrees of IH and empty sella. Clinicians should remain vigilant for this phenomenon. 
Fundus examination, as an easy to implement, noninvasive and inexpensive screening method for $\mathrm{IH}$, should be routinely used in patients with cortisolproducing adrenal adenoma or exogenous hypercortisolism to identify this complication.

\section{Abbreviations}

IH: Intracranial hypertension; IH: Idiopathic intracranial hypertension; ACTH: Adrenocorticotrophic hormone; LDDST: Low-dose dexamethasone suppression test; MRI: Magnetic resonance imaging; CT: Computed tomography; CSF: Cerebrospinal fluid; 11ß-HSD1: 11ß-hydroxysteroid dehydrogenase type 1

\section{Acknowledgments}

The authors thank Dr. Jingxian Zhang (Shanxi Provincial People's Hospital) and Dr. Yuqing Qiao (Jinzhong First Hospital of Shanxi Medical University) for their help with the CT and MRI images. They also thank the patient and her family for their provision of detailed information and image films.

\section{Authors' contributions}

$\mathrm{NZ}$ researched the literature and wrote the first draft. $W Y, X L, L W, Y F$ and $N Z$ were involved in the clinical care of the patient. NZ, YF, WY, XL and LW collected, analyzed and interpreted patient information. NZ is responsible for the integrity of the data and the accuracy of the data analysis. All authors approved the final submitted version.

\section{Funding}

The patient's complete exome sequencing reveals no mutations are detected in HSD11B1, HSD11B2 and H6PD genes involved in modulating cortisol metabolism. The sequencing work was supported by Shanxi Provincial Key Research and Development Project (201803D31131, to Dr. Naiqian Zhao)

\section{Availability of data and materials}

All data related to this report are kept at Second Hospital of Shanxi Medical University (Shanxi Province, China), and are available from the corresponding author on reasonable request.

\section{Declarations}

Ethics approval and consent to participate

All procedures performed in the research were in accordance with the Helsinki declaration. An informed consent was obtained from the patient.

\section{Consent for publication}

Written informed consent was obtained from the patient for publication of this case report and any accompanying images. A copy of the written consent is available for review by the editor of this journal.

\section{Competing interests}

The authors declare no relevant competing interest.

\section{Author details}

${ }^{1}$ Department of Gerontology, Second Hospital of Shanxi Medical University, Wuyi Road 382\#, Taiyuan 030001, China. '2Department of Infectious Diseases, Jinzhong First Hospital of Shanxi Medical University, Huitong South Road 689\#, Jinzhong 030699, China.

Received: 5 October 2021 Accepted: 30 December 2021

Published online: 15 January 2022

\section{References}

1. Toscano S, Lo Fermo S, Reggio E, Chisari CG, Patti F, Zappia M. An update on idiopathic intracranial hypertension in adults: a look at pathophysiology, diagnostic approach and management. J Neurol. 2021;268(9):3249-68. https://doi.org/10.1007/s00415-020-09943-9.

2. Chiloiro S, Giampietro A, Bianchi A, Tartaglione T, Capobianco A, Anile C, et al. DIAGNOSIS OF ENDOCRINE DISEASE: primary empty Sella: a comprehensive review. Eur J Endocrinol. 2017:177(6):R275-85. https://doi. org/10.1530/EJE-17-0505
3. Salpietro V, Polizzi A, Bertè LF, Chimenz R, Chirico V, Manti S, et al. Idiopathic intracranial hypertension: a unifying neuroendocrine hypothesis through the adrenal-brain axis. Neuro Endocrinol Lett. 2012;33(6):569-73.

4. Britton C, Boxhill C, Brust JC, Healton EB, Braun CW, Killian P. Pseudotumor cerebri, empty sella syndrome, and adrenal adenoma. Neurology. 1980;30(3): 292-6. https://doi.org/10.1212/wnl.30.3.292.

5. Tan MG, Worley B, Kim WB, Ten Hove M, Beecker J. Drug-induced intracranial hypertension: a systematic review and critical assessment of drug-induced causes. Am J Clin Dermatol. 2020;21(2):163-72. https://doi. org/10.1007/s40257-019-00485-z.

6. Newton M, Cooper BT. Benign intracranial hypertension during prednisolone treatment for inflammatory bowel disease. Gut. 1994;35(3): 423-5. https://doi.org/10.1136/gut.35.3.423.

7. Markey KA, Uldall M, Botfield H, Cato LD, Miah MA, Hassan-Smith G, et al. Idiopathic intracranial hypertension, hormones, and 11 beta-hydroxysteroid dehydrogenases. J Pain Res. 2016;9:223-32. https://doi.org/10.2147/JPR. S80824.

\section{Publisher's Note}

Springer Nature remains neutral with regard to jurisdictional claims in published maps and institutional affiliations.

Ready to submit your research? Choose BMC and benefit from

- fast, convenient online submission

- thorough peer review by experienced researchers in your field

- rapid publication on acceptance

- support for research data, including large and complex data types

- gold Open Access which fosters wider collaboration and increased citations

- maximum visibility for your research: over $100 \mathrm{M}$ website views per year

At $\mathrm{BMC}$, research is always in progress.

Learn more biomedcentral.com/submission 